\title{
Off-Shore Fly or Die Holograms for Desert Locust Swarms
}

\author{
Dr. Ugur Sevilmis
}

Eastern Mediterranean Agricultural Research Institute, Adana, Turkey

sevilmisugur@yahoo.com

\begin{abstract}
A random walk search was conducted on academic papers to find a method for ecological combat of desert locust. Relatedness of papers and concepts were mainly analysed with the core idea of "Fighting Rooster" vs "Desert Locust " interspecies competition. It was interesting to find a better preator than fighting roosters for locust swarms in the sea. Usage of a technology is required in this theoric approach to modify collective behavior of desert locusts which looks like the achilles heel of swarms.
\end{abstract}

Keywords: Invasion, migration, predation, interspecies competition, süper-organism, swarm intelligence, collective intelligence, multi-species communities

\section{Conclusions}

A locust swarm is a highly adaptive süper-organism using collective behavior and collective intelligence. Complex interactions exists within its interiror and environmental relations coming from genetic evolution of this species. It is hard to totally change its capacity of foraging on herbage due to its high adaptation capacity. The best method to prevent it is to keep them away from terestial ecosystems and keep them off-shore to spend their fats. Just one day will be adequate to destroy a whole swarm; when the night comes. During night time when all individual visual sensors are shut down, the süper-organsim will be fragmented. Under dark and no landing condition, they will spend their energy. Dead bodies of locusts will be the landing zone for the rest of the huge swarm. But predator fishes will be vey happy to hunt 40 and 80 million locusts per square kilometer (a total of around 50 to 100 billion locusts per swarm, representing 100,000 to 200,000 tons of flesh). This can be accomplished by a set of boat-borne holograms of attractive forages on oceans tied to coasts intersecting with possible routes. Keeping swarm unified under incorrect decision is also required. A green road to offshore with first-on-first-off-shut-down of hologram-ships will put swarms totally in unexperienced harsh environment. In the target zone, first-on-first-off shut-down of circular distant positioned off-shore boat-borne-holograms will result with fast energy consuming vortex shaped swarm behaviours during day and maybe night. Phosphorescence may be utilised below boats to attract school of deep-sea preadators. Hologram attraction was found suitable for trapping housefly, Indian meal moth, clothes moth, mosquitoes and common wasps in a patent application of Feldhege et al., (2003) but the reaction of locusts to different types of holograms might be tested before a real field experiment of this fictional approach.

Swarms can't be a cumulative animal cultural evolution trial or nature's evolutionary aim to change the leading species in world..I guess.! But, may not a simple kleptoparasitism also.

\section{Introduction}


A food chain is a succession of organisms that eat other organisms and may in turn be eaten. Ecological theory suggests that complex food webs should not persist due to instability. But real ecosystems often support a large number of interacting species. Without adaptive foragers, food-web complexity destabilizes community composition. Whereas with adaptive foragers, complexity may enhance community persistence through facilitation of dynamical food-web reconstruction. As a result, this buffers environmental fluctuations (Kondoh, 2003).

The trophic level of an organism indicates the position of it in a food web. It gives the number of steps from the start of the chain. A food web starts at trophic level 1 with primary producers such as plants, can move to herbivores at level 2, carnivores at level 3 or higher, and typically finish with apex predators at level 4 or 5 . The path in the chain can form a one-way flow or a food "web". Higher biodiversity in commuities result with more complex trophic paths (Anonymus, 1).

When a trophic level in a food web is suppressed, powerful indirect interactions that can control entire ecosystems named trophic cascades can occure (Anonymus, 2). When identifying potential trophic cascades, it is important to clearly establish the trophic linkages between predators and prey with respect to temporal abundance, demographics, distribution, and diet (Grubbs et al., 2016). For example reduced fishing pressure and weak predator-prey interactions in marine reserves can result with trophic cascades that increase the number of grazing fishes and reduce the coverage of macroalgae on coral reefs (Mumby et al., 2007).

\section{Overexploitation of predators}

Overexploitation of predators is linked to the collapse of a growing number of shallow-water marine ecosystems (Altieri et al., 2012). A food chain model based on trophic cascade theory predicts substantial variance in ecosystem function at time scales near the lifespan of the dominant predator (Carpenter \& Leavitt, 1991). The fear, independent of their direct killing of prey, may cause cascading effects down food webs potentially critical for conserving ecosystem function (Suraci et al., 2016). According to Newsome \& Ripple (2015), top-down processes, via the direct and indirect effects of interspecific competitive killing (no consumption of the kill) or intraguild predation (consumption of the kill), can potentially influence the spatial distribution of terrestrial predators. However, for a distance of up to $200 \mathrm{~km}$ on the edge of wolf distribution, there is a transition zone where the effects of top-down control are weakened, possibly due to the rapid dispersal and reinvasion capabilities of coyotes into areas where wolves are sporadically distributed or at low densities. In nother stuy, bird predators were excluded over a period of 2 years with large, wide-mesh cages in the lower intertidal zone of Tatoosh Island, U.S.A. to determine their effects on sea urchin abundance and macro-algal abundance and diversity. Bird predation directly reduced urchin abundance by $45-59 \%$. By reducing urchin grazing, birds indirectly increased algal cover 24-fold, and increased algal taxonomic richness 6-fold across all replicates (Wootton, 1995).

Understanding patterns of distribution of organisms and factors underlying them is a fundamental goal of ecology (Heatherly et al., 2005). According to Luskin et al., (2017), native species that forage in farmland may increase their local plentifulness and affect neighboring ecosystems within their landscape. They used two decades of ecological data from a protected rainforest in Malaysia to illutrate how subsidies from neighboring oil palm plantations triggered powerful secondary 'cascading' effects on natural habitats located $>1.3 \mathrm{~km}$ away. They found that oil palm fruit drove 100-fold increases in crop-raiding native wild boar (Sus scrofa); wild boar used thousands of understory plants to construct birthing nests in the pristine forest interior; and nest building caused a $62 \%$ decline in forest tree sapling density over the 24-year 
study period. The long-term, landscape-scale indirect effects from agriculture suggest its full ecological footprint may be larger in extent than is currently recognized. Cross-boundary subsidy cascades may be widespread in both terrestrial and marine ecosystems and present significant conservation challenges.

\section{Species invasion}

Species invasions are extremely common. Management actions targeting the whole landscape or ecosystem may provide better cost-effective protection against the invasive species compared to a species-by-species approach (Marvier et al., 2004). Broad-scale conservation of habitats is increasingly being recognized as a more effective means of protecting species or landscapes than single-species efforts (Noss et al., 1997).

\section{Habitat fragmentation}

Habitat fragmentation means a loss of habitat, reduced land piece size and an increasing distance between land pieces, but also an increase of new habitat (Andren, 1994).

\section{Ecological carrying capacity}

A balanced ecological carrying capacity and understanding its importance are important to achieve sustainable development for human kind (Liu et al., 2011, 2012). The term ecological balance refers to the stability of life-forms (Miller, 1972).

\section{Animal migration}

Animal migration surely ranks as one of nature's most visible and widespread phenomena. Every day, somewhere, animals are moving. The migrants span the animal kingdom, from whales to dragonflies (Wilcove \& Wikelski, 2008). Animal migrations are often magnificient, and migratory species harbor zoonotic pathogens to humans (Altizer et al., 2011). Animal groups, such as schools of fish, flocks of birds, swarms of locusts, and herds of wildebeest, show a variety of behaviors including swarming about a food source or migrating over large distances in aligned groups. These collective behaviors are often advantageous to groups, allowing them to increase their harvesting efficiency, to follow better migration routes, to improve their aerodynamic, and to avoid predation (Cuevaset al., 2012). Understanding and even defining what constitutes animal interactions is still a challenging problem (Lord et al., 2016).

\section{Social interactions with other group members}

Animals living in groups make movement decisions that depend, among other factors, on social interactions with other group members (Pérez-Escudero \& de Polavieja, 2011). Collective behaviour has primarily been studied in animal groups such as colonies of insects, birds and fishes. Although less studied, collective behaviour also occurs in microorganisms (Reid \& Latty, 2016). According to Ballerini et al., (2008), numerical models indicate that collective animal behavior may emerge from simple local rules of interaction among the individuals. However, knowledge is little on the nature of these interactions, so models and theories mostly use aprioristic assumptions. By reconstructing the three-dimensional positions of individual birds in airborne flocks of a few thousand members, they showed that the interaction does not depend on the metric distance, as most of the current models and theories assume, but rather on the topological distance. Each bird interacts on average with a fixed number of neighbors (six to seven), rather than with all neighbors within a fixed metric distance. Interactions between starling flocks birds have a topological rather than metric nature, each individual interacting 
with a fixed number of neighbors irrespective of their distances (Cavagna et al., 2010). Confusion effect is seen to be a general problem for predators (Schradin, 2000).

\section{Swarming}

One hypothesis is that swarms arise because the multiple moving prey causes confusion for attacking predators (Olson et al., 2013). The swarm behaviour can be controlled by different localizations of attractants and repellents (dangerous places) (Schumann, 2017). When confronted with a swarm of their prey, many predators become confused and are less successful in their attacks (Jeschke \& Tollrian, 2005). A negative relationship between group size and levels of individual awakeness is widespread in socially feeding vertebrates. The main explanation of this 'group-size effect', (many-eyes hypothesis) says that as group size increases, more eyes are scanning the environment for predators. So an individual forager can spend more time for feeding. In addition, individuals monitor the alertness behaviour of their groupmates to tüne their own alertness level (Lima, 1995).

\section{Desert locust swarms}

A single desert locust swarm can cover up to 1200 square kilometers and can contain between 40 and 80 million locusts per square kilometer (a total of around 50 to 100 billion locusts per swarm, representing 100,000 to 200,000 tons, considering an average mass of 2 grams per locust). The locust can live between three and six months, and there is a ten to 16 -fold increase in locust numbers from one generation to the next (Anonymus, 3).

The ability to change phase between solitarious and gregarious forms in response to population density is a key feature of locusts and is central to their occasional yet catastrophic impact on humans. Phase polymorphism is an extreme form of phenotypic plasticity. The most labile phase characteristic is behaviour (Simpson et al., 1999).

\section{Collective animal behavior}

Collective animal behavior is a form of social coordinated behavior of large groups of similar animals as well as emergent properties of these groups. This include the costs and benefits of group membership, the transfer of information across the group, the group decision-making process, and group locomotion and synchronization. Many functions of animal aggregations have been proposed and may be grouped into four categories: social and genetic, antipredator, enhanced foraging, and increased locomotion efficiency (Anonymus, 4).

\section{Proto-cooperation}

Herbert-Read et al., (2016) present evidence of a novel form of group hunting. Individual sailfish (Istiophorus platypterus) makes alternate attacks with other group members on their schooling prey (Sardinella aurita). While only $24 \%$ of attacks result in prey capture, multiple prey are injured in $95 \%$ of attacks. How quickly prey are captured is positively correlated with the level of injury of the school so the hunters can benefit from other's attacks on the prey. They show that group hunting provides major efficiency gains (prey caught per unit time) for groups of up to 70 members. Also a free riding strategy, where some individuals wait until the prey are sufficiently injured before attacking, is only beneficial if the cost of attacking is high. In lions, foraging success does not change significantly with group size when prey is abundant (Packer et al., 1990).

\section{Modification of prey behaviour by predator}

To trap prey, humpback whales sometimes use 'bubble nets' in the form of hollow cylinders. The cylinder wall contains a dense population of bubbles, but the interior is comparatively 
bubble-free. A group of whales may cooperate, diving and then rising in a helix, releasing bubbles to form nets of 3 to 30 metres diameter. The prey congregate in the bubblefree centre and are then consumed by the whales, which rise from below. Why prey refuse to escape through the walls is probably reasoning from acoustic properties of the nets (Leighton et al., 2004).

In predator-prey interactions, the efficiency of the predator is dependent on characteristics of both the predator and the prey, as well as the structure of the environment (Eklöv \& Diehl, 1994).

\section{Predator size-prey size relationships}

Size relationships are central in trophic linkages within food webs (Owen-Smith \& Mills, 2008). Predator-prey body size relationships influence food chain length, trophic structure, transfer efficiency and interaction strength (Barnes et al., 2010).

Prey must pass through a vulnerable stage before achieving a predator-invulnerable size. As environmental productivity increases, the impact of predators decreases because more individuals turn and remain in the invulnerable adult stage. At low productivity, the small species wins competition where the system is strongly consumer controlled. At high productivity, the large species wins due to the presence of predators where the system becomes less consumer controlled. At intermediate productivity, either the small or the large species can win depending on initial conditions where the system can be either strongly or weakly consumer controlled (Chase, 1999).

An experimental study was carried out on prey handling time (from initial seizure of prey to completion of swallowing movements) in the grass pickerel (Esox americanus vermiculatus), using bluegill (Lepomis macrochirus) as prey. For individuals of the same mouth width (20 $\mathrm{mm}$ ), handling time was $40-80 \%$ less in Esox for bluegill prey of total length $20-50 \mathrm{~mm}$. "Optimal" and maximum size of prey consumed were 56 and $46 \%$ larger, respectively, for the esocid (Hoyle \& Keast, 1988). Aquatic organisms, especially fishes, exhibit exceptional diversity in mouth morphology and this variation has been shown to influence foraging patterns (Detmer et al., 2018).

\section{Foraging}

How animals find food in dynamic natural environments where they possess little or no knowledge of location of resources? Foraging theory says that in environments with distributed target resources, where forager knowledge about locations of the resources is incomplete, Lévy flight movements optimize the success of random searches in model simulations (Humphries et al., 2012).

Variation in foraging success among 284 colour-ringed European blackbirds (Turdus merula) was studied in U.K. One-year-old birds foraging on lawns were half as successful at getting large prey as 2-year-old birds. There was no change in foraging success among birds aged $>3$. Same aged males and females was similar at foraging success (Desrochers, 1992). The composition of an animal group can highly effect the survival and success of its members (Dyer et al., 2009).

Many studies have demonstrated a negative relationship between increasing habitat complexity and predator foraging success. These studies suggest a non-linear relationship, and some "threshold level" of complexity is required before foraging success is significantly reduced (Gotceitas \& Colgan, 1989). 
Foragers produce fat as an energy reserve to escape starvation. Reserves are required to survive when energy intake is not possible. However, building maximum possible body reserves may be detrimental due to the cost of carrying fat (Ekman \& Hake, 1990). Establishing where and when predators forage is essential to understanding trophic interactions (Austin et al., 2006).

\section{Group foraging}

Group foraging has been proposed as an important factor for the evolution of sociality (Dechmann et al., 2009). Individual role specialization during group hunting is very rare in mammals (Gazda et al., 2005). Many bat species live in groups. Some of them live in highly complex social systems. Increased foraging efficiency through passive information transfer in species foraging for short-living insects has been postulated as a reason for group formation of male bats (Dechmannet al., 2010). Cooperative hunting might have important implications for the evolution of sociality and advanced cognitive abilities (Bailey et al., 2013). Group hunting in social carnivores is thought to have evolved by natural selection for increased efficiency of prey capture, increased prey size caught or defence of the kill against intra-and interspecific kleptoparasitism (Carbone et al., 1997). Living in groups facilitates prey capture but hunting success reach peak at small group sizes. The hunting success of predators and predation risk of individual prey decrease with increasing prey group size (Krause \& Godin, 1995). Nonlinear trends in group hunting success reflect a switch from cooperation to free riding (MacNulty et al., 2012). Successful collective decisionmaking in groups of animals depends on accurate choices during group cohesion. However, increasing accuracy and/or cohesion frequently decreases decision speed and vice-versa. This is widespread in animal decision-making and results with various decision-making strategies that use either speed or accuracy depending on the context (Stroeymeyt et al., 2010). The range of prey sizes captured by co-occurring species of group-hunting social spiders positively correlates with their level of sociality (Harwood \& Avilés, 2013). Differences between species in the hunting with respect to communication, coordination and food sharing might be a reflection of differences in cognitive abilities (Strübin et al., 2011). The benefits of living in groups may increase with groupsize but this will depend on predator species or hunting mode (Cresswell \& Quinn, 2010).

\section{Collective decision making}

Collective decision making is a main organization mechanisms in social insects. But, individual decision making play an important role depending on the foraging behaviour type. In the termite-hunting ant species (Megaponera analis), information of foraging sites is collected and conveyed to the colony by only a few individual as accurately as possible to optimize their foraging behaviour (Frank \& Linsenmair, 2017). Pooling information can help groups to make better decisions than individuals. Group size is also thought to influence the accuracy of decision making with enormous variation in the size and composition of animal societies. Animals need to make decisions in dynamic environments and environmental conditions can alter or invert the advantage of group size (Cronin, 2016)

\section{Challenge hypothesis}

In male vertebrates, androgen levels show strong patterns throughout the year and play an important role in the frequency, intensity and persistence of aggression (Goymann et al., 2007). Territorial aggression is regulated by androgens which is well established in males. In many species, females also Show aggressive behavior 
(Desjardins et al., 2006). The challenge hypothesis as established for adult birds, is also applicable for aggressive behavior in young birds outside the sexual context. A phase of priming with testosterone is necessary to reach to high behavioral responsiveness to a challenge (Ros et al., 2002). Testosterone has been related to agonistic interactions, while glucocorticoids have been related to social stress, basicly during interactions of dominance (Soto-Gamboa et al., 2005). Many animals adapt to rapidly changing social environments by using social information to modulate their hormone titres. By modulation of hormone titres, individuals can match their behaviour to their current social environment and avoid costs associated with prolonged high hormone titres. Most work on social responsiveness of hormone titres has focused on androgens in vertebrates but there is mounting evidence that insect hormones, especially juvenile hormone, may respond to social stimuli in ways that parallel androgens in vertebrates (Tibbetts \& Crocker, 2014). Testosterone levels and aggression in male adult animals are closely associated with intense reproductive competition for the access to females (Cristóbal-Azkarate et al., 2006). The challenge hypothesis says that plasma testosterone concentration is high when male-male competitions are high and low when males are engaged in paternal care. In monogamous species, testosterone concentration increases at the beginning of the breeding period and decreases after egg laying (Parisot et al., 2005). Male-female interactions are more important than male-male interactions in for rapid changes in plasma androgen concentrations (Goymann et al., 2019).

Under the threat of predation, animals can decrease their risk by moving towards other individuals and form compact groups (Kimbell \& Morrell, 2015). Individuals watch the decisions of others before making their own decisions. This technique generally results in the correct decision but sometimes with incorrect decision. Consensus decision-making, a form of collective intelligence, thus effectively uses information from multiple sources to generally reach the correct conclusion (Sumpter et al. 2008).

\section{Swarm intelligence}

Swarm intelligence is a kind of problem-solving ability emerging from the interactions of simple information-processing units (Kennedy, 2006). Ants, bees and termites - all social insects show impressive problem-solving capabilities. Properties associated with their group behaviour like self-organisation, robustness and flexibility are characteristics for optimisation, control or task execution (Bonabeau et al., 1999).

Swarm intelligence refers to collective intelligence. Natural scientist have been studying the social insects' efficiency of solving complex problems like finding the shortest path between their nest and food source or organizing their nests. These insects are not sophisticated individually, they make wonders as a swarm by interaction with each other and their environment (Saka et al., 2013).

\section{Collective intelligence}

Collective intelligence is the ability of a group to solve more problems than its individual members (Heylighen, 1999). Individual decision making can often be wrong due to misinformation, impulses, or biases. But, collective decision making can be surprisingly accurate (Landemore, 2017). Collective intelligence, which aggregates the shared information from large crowds, is often negatively impacted by unreliable information sources with the low quality data. This becomes a barrier to the effective use of collective intelligence in diversified applications (Qi et al., 2013). 
A collective intelligence consists of a large number of quasi-independent, stochastic agents, interacting locally both among themselves as well as with an active environment, in the absence of hierarchical organization which is capable of adaptive behavior. The major concepts arising from collective intelligence are stochastic determinism, interactive determinism, nondirected communication, nonrepresentational contextual dependency, stigmergy which are illustrated by using ant behavior (Sulis, 1997).

It describes any cooperative enterprise in which individuals pool their resources to enhance task achievement. Also occurs only when there is an interaction or cross-fertilization between participants in the task. Collective intelligence is generally more innovative, though not necessarily more effective, than the intellectual capability of individuals working alone. It may be passed on, but is not biologically transmitted (Weschsler, 1971).

Complex adaptive systems consist of a large number of interacting agents. Agents are goaldirected, cognitive individuals capable of perception, information processing and action. However, agents are intrinsically "bounded" in their rational understanding of the system they belong to, and its global organization tends to emerge from local interactions, resulting in a coordination of the agents and their actions. This coordination minimizes conflict while facilitating cooperation or synergy. The basic mechanism is the reinforcement of synergetic interactions and the suppression of conflictual ones. As a result, the system as a whole starts to behave like an integrated cognitive "superagent" (Heylighen, 2013).

\section{Literatures}

Altieri, A. H., Bertness, M. D., Coverdale, T. C., Herrmann, N. C., \& Angelini, C. (2012). A trophic cascade triggers collapse of a salt-marsh ecosystem with intensive recreational fishing. Ecology, 93(6), 1402-1410.

Altizer, S., Bartel, R., \& Han, B. A. (2011). Animal migration and infectious disease risk. science, 331(6015), 296-302.

Andren, H. (1994). Effects of habitat fragmentation on birds and mammals in landscapes with different proportions of suitable habitat: a review. Oikos, 355-366.

Anonymus 1. https://en.wikipedia.org/wiki/Trophic level

Anonymus 2. https://en.wikipedia.org/wiki/Trophic cascade

Anonymus 3. https://en.wikipedia.org/wiki/Desert locust

Anonymus 4. https://en.wikipedia.org/wiki/Collective animal behavior

Austin, D., Bowen, W. D., McMillan, J. I., \& Iverson, S. J. (2006). Linking movement, diving, and habitat to foraging success in a large marine predator. Ecology, 87(12), 3095-3108.

Bailey, I., Myatt, J. P., \& Wilson, A. M. (2013). Group hunting within the Carnivora: physiological, cognitive and environmental influences on strategy and cooperation. Behavioral Ecology and Sociobiology, 67(1), 1-17.

Ballerini, M., Cabibbo, N., Candelier, R., Cavagna, A., Cisbani, E., Giardina, I., ... \& Viale, M. (2008). Interaction ruling animal collective behavior depends on topological rather than metric distance: Evidence from a field study. Proceedings of the national academy of sciences, 105(4), 1232-1237. 
Barnes, C., Maxwell, D., Reuman, D. C., \& Jennings, S. (2010). Global patterns in predatorprey size relationships reveal size dependency of trophic transfer efficiency. Ecology, 91(1), 222-232.

Bonabeau, E., Dorigo, M., Marco, D. D. R. D. F., Theraulaz, G., \& Théraulaz, G. (1999). Swarm intelligence: from natural to artificial systems (No. 1). Oxford university press.

Carbone, C., Du Toit, J. T., \& Gordon, I. J. (1997). Feeding success in African wild dogs: does kleptoparasitism by spotted hyenas influence hunting group size?. Journal of animal Ecology, 318-326.

Carpenter, S. R., \& Leavitt, P. R. (1991). Temporal variation in a paleolimnological record arising from a trophic cascade. Ecology, 72(1), 277-285.

Cavagna, A., Cimarelli, A., Giardina, I., Parisi, G., Santagati, R., Stefanini, F., \& Tavarone, R. (2010). From empirical data to inter-individual interactions: unveiling the rules of collective animal behavior. Mathematical Models and Methods in Applied Sciences, 20(supp01), 14911510.

Chase, J. M. (1999). Food web effects of prey size refugia: variable interactions and alternative stable equilibria. The American Naturalist, 154(5), 559-570.

Cresswell, W., \& Quinn, J. L. (2010). Attack frequency, attack success and choice of prey group size for two predators with contrasting hunting strategies. Animal Behaviour, 80(4), 643648.

Cristóbal-Azkarate, J., Chavira, R., Boeck, L., Rodríguez-Luna, E., \& Veàl, J. J. (2006). Testosterone levels of free-ranging resident mantled howler monkey males in relation to the number and density of solitary males: a test of the challenge hypothesis. Hormones and behavior, 49(2), 261-267.

Cronin, A. L. (2016). Group size advantages to decision making are environmentally contingent in house-hunting Myrmecina ants. Animal Behaviour, 118, 171-179.

Cuevas, E., Gonzalez, M., Zaldivar, D., Perez-Cisneros, M., \& García, G. (2012). An algorithm for global optimization inspired by collective animal behavior. Discrete Dynamics in Nature and Society, 2012.

Dechmann, D. K., Heucke, S. L., Giuggioli, L., Safi, K., Voigt, C. C., \& Wikelski, M. (2009). Experimental evidence for group hunting via eavesdropping in echolocating bats. Proceedings of the Royal Society B: Biological Sciences, 276(1668), 2721-2728.

Dechmann, D. K., Kranstauber, B., Gibbs, D., \& Wikelski, M. (2010). Group hunting-a reason for sociality in molossid bats?. PLoS one, 5(2).

Desjardins, J. K., Hazelden, M. R., Van der Kraak, G. J., \& Balshine, S. (2006). Male and female cooperatively breeding fish provide support for the "Challenge Hypothesis". Behavioral Ecology, 17(2), 149-154.

Desrochers, A. (1992). Age and foraging success in European blackbirds: variation between and with individuals. Animal Behaviour, 43(6), 885-894.

Detmer, T. M., Einfalt, L. M., Parkos, J. J., \& Wahl, D. H. (2018). Comparison of mouth morphology and prey size selection among three esocid taxa. Environmental Biology of Fishes, 101(3), 449-458. 
Dyer, J. R., Croft, D. P., Morrell, L. J., \& Krause, J. (2009). Shoal composition determines foraging success in the guppy. Behavioral Ecology, 20(1), 165-171.

Eklöv, P., \& Diehl, S. (1994). Piscivore efficiency and refuging prey: the importance of predator search mode. Oecologia, 98(3-4), 344-353.

Ekman, J. B., \& Hake, M. K. (1990). Monitoring starvation risk: adjustments of body reserves in greenfinches (Carduelis chloris L.) during periods of unpredictable foraging success. Behavioral Ecology, 1(1), 62-67.

Feldhege, M., Roreger, M., Kloczko, M., \& Schnitzler, I. (2003). U.S. Patent Application No. 10/465,213.

Fitzgerald, A. J., Kalof, L., \& Dietz, T. (2009). Slaughterhouses and increased crime rates: An empirical analysis of the spillover from "The Jungle" into the surrounding community. Organization \& Environment, 22(2), 158-184.

Frank, E. T., \& Linsenmair, K. E. (2017). Individual versus collective decision making: Optimal foraging in the group-hunting termite specialist Megaponera analis. Animal Behaviour, 130, 27-35.

Gazda, S. K., Connor, R. C., Edgar, R. K., \& Cox, F. (2005). A division of labour with role specialization in group-hunting bottlenose dolphins (Tursiops truncatus) off Cedar Key, Florida. Proceedings of the Royal Society B: Biological Sciences, 272(1559), 135-140.

Gotceitas, V., \& Colgan, P. (1989). Predator foraging success and habitat complexity: quantitative test of the threshold hypothesis. Oecologia, 80(2), 158-166.

Goymann, W., Landys, M. M., \& Wingfield, J. C. (2007). Distinguishing seasonal androgen responses from male-male androgen responsiveness-revisiting the challenge hypothesis. Hormones and Behavior, 51(4), 463-476.

Goymann, W., Moore, I. T., \& Oliveira, R. F. (2019). Challenge hypothesis 2.0: a fresh look at an established idea. BioScience, 69(6), 432-442.

Grubbs, R. D., Carlson, J. K., Romine, J. G., Curtis, T. H., McElroy, W. D., McCandless, C. T., ... \& Musick, J. A. (2016). Critical assessment and ramifications of a purported marine trophic cascade. Scientific Reports, 6, 20970.

Harwood, G., \& Avilés, L. (2013). Differences in group size and the extent of individual participation in group hunting may contribute to differential prey-size use among social spiders. Biology letters, 9(6), 20130621.

Heatherly, T., Whiles, M. R., Gibson, D. J., Collins, S. L., Huryn, A. D., Jackson, J. K., \& Palmer, M. (2005). Stream insect distributional patterns and metapopulation models: effects of spatial scale and sampling intensities. In AGU Spring Meeting Abstracts.

Herbert-Read, J. E., Romanczuk, P., Krause, S., Strömbom, D., Couillaud, P., Domenici, P., ... \& Krause, J. (2016). Proto-cooperation: group hunting sailfish improve hunting success by alternating attacks on grouping prey. Proceedings of the Royal Society B: Biological Sciences, 283(1842), 20161671.

Heylighen, F. (1999). Collective Intelligence and its Implementation on the Web: algorithms to develop a collective mental map. Computational \& Mathematical Organization Theory, 5(3), 253-280. 
Heylighen, F. (2013). Self-organization in Communicating Groups: the emergence of coordination, shared references and collective intelligence. In Complexity Perspectives on Language, Communication and Society (pp. 117-149). Springer, Berlin, Heidelberg.

Hoyle, J. A., \& Keast, A. (1988). Prey handling time in two piscivores, Esox americanus vermiculatus and Micropterus salmoides, with contrasting mouth morphologies. Canadian Journal of Zoology, 66(2), 540-542.

Humphries, N. E., Weimerskirch, H., Queiroz, N., Southall, E. J., \& Sims, D. W. (2012). Foraging success of biological Lévy flights recorded in situ. Proceedings of the National Academy of Sciences, 109(19), 7169-7174.

Kennedy, J. (2006). Swarm intelligence. In Handbook of nature-inspired and innovative computing (pp. 187-219). Springer, Boston, MA.

Kimbell, H. S., \& Morrell, L. J. (2015). 'Selfish herds' of guppies follow complex movement rules, but not when information is limited. Proceedings of the Royal Society B: Biological Sciences, 282(1816), 20151558.

Kondoh, M. (2003). Foraging adaptation and the relationship between food-web complexity and stability. Science, 299(5611), 1388-1391.

Krause, J., \& Godin, J. G. J. (1995). Predator preferences for attacking particular prey group sizes: consequences for predator hunting success and prey predation risk. Animal Behaviour, 50(2), 465-473.

Landemore, H. (2017). Democratic reason: Politics, collective intelligence, and the rule of the many. Princeton University Press.

Leighton, T. G., Richards, S. D., \& White, P. R. (2004). Trapped within a wall of sound. Acoustics Bulletin, 29, 24-29.

Lima, S. L. (1995). Back to the basics of anti-predatory vigilance: the group-size effect. Animal Behaviour, 49(1), 11-20.

Liu, D., Feng, Z. M., \& Yang, Y. Z. (2012). Ecological balance between supply and demand in China using ecological footprint method. Journal of natural resources, 27(4), 614-624.

Liu, D., Feng, Z., Yang, Y., \& You, Z. (2011). Spatial patterns of ecological carrying capacity supply-demand balance in China at county level. Journal of Geographical Sciences, 21(5), 833.

Lord, W. M., Sun, J., Ouellette, N. T., \& Bollt, E. M. (2016). Inference of causal information flow in collective animal behavior. IEEE Transactions on Molecular, Biological and Multi-Scale Communications, 2(1), 107-116.

Luskin, M. S., Brashares, J. S., Ickes, K., Sun, I. F., Fletcher, C., Wright, S. J., \& Potts, M. D. (2017). Cross-boundary subsidy cascades from oil palm degrade distant tropical forests. Nature communications, 8(1), 1-7.

M. Jeschke, J., \& Tollrian, R. (2005). Effects of predator confusion on functional responses. Oikos, 111(3), 547-555.

MacNulty, D. R., Smith, D. W., Mech, L. D., Vucetich, J. A., \& Packer, C. (2012). Nonlinear effects of group size on the success of wolves hunting elk. Behavioral Ecology, 23(1), 75-82. 
Marvier, M., Kareiva, P., \& Neubert, M. G. (2004). Habitat destruction, fragmentation, and disturbance promote invasion by habitat generalists in a multispecies metapopulation. Risk Analysis: An International Journal, 24(4), 869-878.

Miller, A. R. (1972). Ecological balance in semi-enclosed seas. Envtl. Aff., 2, 191.

Mumby, P. J., Harborne, A. R., Williams, J., Kappel, C. V., Brumbaugh, D. R., Micheli, F., ... \& Blackwell, P. G. (2007). Trophic cascade facilitates coral recruitment in a marine reserve. Proceedings of the National Academy of Sciences, 104(20), 8362-8367.

Newsome, T. M., \& Ripple, W. J. (2015). A continental scale trophic cascade from wolves through coyotes to foxes. Journal of Animal Ecology, 84(1), 49-59.

Noss, R. F., O'Connell, M., \& Murphy, D. D. (1997). The science of conservation planning: habitat conservation under the Endangered Species Act. Island Press.

Olson, R. S., Hintze, A., Dyer, F. C., Knoester, D. B., \& Adami, C. (2013). Predator confusion is sufficient to evolve swarming behaviour. Journal of The Royal Society Interface, 10(85), 20130305.

Owen-Smith, N., \& Mills, M. G. (2008). Predator-prey size relationships in an African largemammal food web. Journal of Animal Ecology, 77(1), 173-183.

Packer, C., Scheel, D., \& Pusey, A. E. (1990). Why lions form groups: food is not enough. The American Naturalist, 136(1), 1-19.

Parisot, M., Tanvez, A., Lacroix, A., Vallet, E., Béguin, N., \& Leboucher, G. (2005). Social competition and plasma testosterone profile in domesticated canaries: an experimental test of the challenge hypothesis. Hormones and behavior, 48(2), 225-232.

Pérez-Escudero, A., \& de Polavieja, G. (2011). Collective animal behavior from Bayesian estimation and probability matching. Nature Precedings, 1-1.

Qi, G. J., Aggarwal, C. C., Han, J., \& Huang, T. (2013, May). Mining collective intelligence in diverse groups. In Proceedings of the 22nd international conference on World Wide Web (pp. 1041-1052).

Reid, C. R., \& Latty, T. (2016). Collective behaviour and swarm intelligence in slime moulds. FEMS microbiology reviews, 40(6), 798-806.

Ros, A. F., Dieleman, S. J., \& Groothuis, T. G. (2002). Social stimuli, testosterone, and aggression in gull chicks: support for the challenge hypothesis. Hormones and Behavior, 41(3), 334-342.

Saka, M. P., Doğan, E., \& Aydogdu, I. (2013). Analysis of Swarm Intelligence-Based Algorithms for Constrained Optimization. In Swarm Intelligence and Bio-Inspired Computation (pp. 25-48). Elsevier.

Scharf, F. S., Juanes, F., \& Rountree, R. A. (2000). Predator size-prey size relationships of marine fish predators: interspecific variation and effects of ontogeny and body size on trophicniche breadth. Marine Ecology Progress Series, 208, 229-248.

Schradin, C. (2000). Confusion effect in a reptilian and a primate predator. Ethology, 106(8), 691-700.

Schumann, A. (2017). Group theory and p-adic valued models of swarm behaviour. Mathematical Methods in the Applied Sciences, 40(18), 7438-7452. 
Simpson, S. J., McCaffery, A. R., \& Haegele, B. F. (1999). A behavioural analysis of phase change in the desert locust. Biological Reviews, 74(4), 461-480.

Soto-Gamboa, M., Villalón, M., \& Bozinovic, F. (2005). Social cues and hormone levels in male Octodon degus (Rodentia): a field test of the challenge hypothesis. Hormones and Behavior, 47(3), 311-318.

Stroeymeyt, N., Giurfa, M., \& Franks, N. R. (2010). Improving decision speed, accuracy and group cohesion through early information gathering in house-hunting ants. PLoS one, 5(9).

Strübin, C., Steinegger, M., \& Bshary, R. (2011). On group living and collaborative hunting in the yellow saddle goatfish (Parupeneus cyclostomus) 1. Ethology, 117(11), 961-969.

Sulis, W. (1997). Fundamental concepts of collective intelligence. Nonlinear Dynamics, Psychology, and Life Sciences, 1(1), 35-53.

Sumpter, D. J., Krause, J., James, R., Couzin, I. D., \& Ward, A. J. (2008). Consensus decision making by fish. Current Biology, 18(22), 1773-1777.

Suraci, J. P., Clinchy, M., Dill, L. M., Roberts, D., \& Zanette, L. Y. (2016). Fear of large carnivores causes a trophic cascade. Nature communications, 7, 10698.

Tibbetts, E. A., \& Crocker, K. C. (2014). The challenge hypothesis across taxa: social modulation of hormone titres in vertebrates and insects. Animal Behaviour, 92, 281-290.

Weschsler, D. (1971). Concept of collective intelligence. American Psychologist, 26(10), 904.

Wilcove, D. S., \& Wikelski, M. (2008). Going, going, gone: is animal migration disappearing. PLoS biology, 6(7).

Wootton, J. T. (1995). Effects of birds on sea urchins and algae: a lower-intertidal trophic cascade. Ecoscience, 2(4), 321-328. 